Joel Krueger, Giovanna Colombetti

Affective affordances and psychopathology

\title{
Abstract: Affective affordances and psychopathology
}

Self-disorders in depression and schizophrenia have been the focus of much recent work in phenomenological psychopathology. But little has been said about the role the material environment plays in shaping the affective character of these disorders. In this paper, we argue that enjoying reliable (i.e., trustworthy) access to the things and spaces around us - the constituents of our material environment - is crucial for our ability to stabilize and regulate our affective life on a day-to-day basis. These things and spaces often play an ineliminable role in shaping what we feel and how we feel it; when we interact with them, they contribute ongoing feedback that "scaffolds" the character and temporal development of our affective experiences. However, in some psychopathological conditions, the ability to access these things and spaces becomes disturbed. Individuals not only lose certain forms of access to the practical significance of the built environment but also to its regulative significance, too - and the stability and organization of their affective life is compromised. In developing this view, we discuss core concepts like "affordance spaces", "scaffolding", and "incorporation". We apply these concepts to two case studies, severe depression and schizophrenia, and we show why these cases support our main claim. We conclude by briefly considering implications of this view for developing intervention and treatment strategies.

Keywords: Affordances, Affect, Scaffolding, Depression, Schizophrenia.

\section{Introduction}

This paper explores connections between affective disorders in psychopathology and the individual's disturbed relationship with their material environment. While much recent work in phenomenological psychopathology has focused on self-disorders in conditions like depression and schizophrenia, much less has been said about the role the material environment plays in shaping the affective character of these disorders. ${ }^{1}$ We address this lacuna.

1 According to the self-disorder model (Sass 2014; Sass, Parnas 2003), the core disturbance of schizophrenia is grounded in a disturbance of the "minimal self", or basic selfawareness said to be an invariant structural feature of consciousness. Self-disturbances are 
Our main claim is this: experiencing reliable (i.e., trustworthy) access to the things and spaces around us - the constituents of our material environment - is crucial for our ability to stabilize and regulate our affective life on a day-to-day basis. These things and spaces often play an ineliminable role in shaping both what we feel and how we feel it; when we interact with them, they contribute ongoing feedback that "scaffolds" the character and temporal development of our affective experiences like moods and emotions. However, in psychopathological conditions like severe depression and schizophrenia, the ability to access these things and spaces can become disturbed. As a result, individuals not only lose access to the practical significance of the built environment but also to its regulative significance, too - and the stability and organization of their affective life is compromised.

First, we do some background work and introduce core concepts like "affordance spaces", "scaffolding", and "incorporation". Next, we apply these concepts to two case studies: severe depression and schizophrenia. We show why these cases support our main claim. We then conclude by briefly considering the way this approach might suggest the need to consider new forms of intervention and treatment.

\section{Constructing affordance spaces}

James Gibson's notion of an "affordance" characterizes how organisms perceive and respond to features of their environment. For Gibson, the environment is not originally encountered as a neutral space to which we subsequently assign meaning. Rather, it is perceived from the start as furnishing action possibilities we can realize when we are situated within that environment. These action possibilities are specified relationally, both by features of things we experience as well as by the structure of our body and things our bodies can do.

For example, when we walk into our office, we perceive that space as affording a range of possible actions: we can walk over to our desk and sit down in the chair, reach for and retrieve a book from the shelf, water our plants, or lie down on the floor and take a nap. We can do these things not just because objects around us have certain structures and properties affording these actions (e.g., the chair's structure invites sitting, the keyboard typing), but also because we possess the embodied capacities needed to detect and respond to these affordances. An infant will not experience our

found in depressive experience, too, although they seem to be more directly connected to a diminished sense of agency and affectivity instead of fundamental first-person structures underlying all experience (Sass, Pienkos 2013b). We return to some of these ideas below. 
chair as affording sitting or keyboard typing; the range of their affordances is restricted relative to an adult perceiver. Nevertheless, they will experience our office floor as affording crawling or napping since these actions fall within the scope of their developmental constraints.

Importantly, affordances are not just determined by an individual's bodily capacities. They are also determined by an object or environment's sociocultural significance. Because affordances are always found within a shared world, they are irreducibly social. Gibson puts the point this way:

It is a mistake to separate the natural from the artificial as if there were two environments... It is also a mistake to separate the cultural environment from the natural environment... There is only one world, however diverse, and all animals live in it, although we human animals have altered it to suit ourselves (Gibson 1986, p. 130).

For example, the "natural" character of nuts in a dish at a cocktail party mean that they afford being grasped all at once. But such activity is generally frowned upon; sociocultural norms constrain the range of possible actions available in that space. A hungry child unaware of these norms, however, will not be so constrained and may eagerly plunge their hand into the bowl and eat all the nuts at the same time.

As we navigate everyday life, we thus perceive "affordance spaces": richly-structured environments organized by a range of possibilities provided by changes in our body and the surrounding environment. An individual's affordance space is defined by multiple factors, including evolution (the fact that she has hands, walks upright, etc.), development (her particular lifestage and skill set), and social and cultural practices (normative constraints) (Gallagher 2017, p. 174; see also Chemero 2009). The affordance spaces of an adult human perceiver will differ from those of a bat due to evolutionary differences; developmental factors mean that we inhabit different affordance spaces than infants do; and when we travel to a new country for the first time, we lack mastery of the local sociocultural affordances (cultural practices, styles of communication, etc.) due to an unfamiliarity with the relevant normative constraints.

The notion of an "affordance space" is a useful conceptual tool for clarifying how features of our embodiment and agency determine how the world shows up for us, experientially. Additionally, it highlights the reciprocity between embodied agents and their world - that is, the way agents detect and respond to action possibilities that covary with an agent's bodily skills and the biological, material, and social structures of her surroundings (Rietveld, Kiverstein 2014). But we perceive environments as affording more than just practical actions (e.g., reaching for and grasping a beer bottle or nuts in a bowl). What is often overlooked in these debates is that we also perceive affective affordances (Hufendiek 2016). 
For our purposes, what this means is that we perceive people, places, and things as affording regulative opportunities to amplify, suppress, extend, enrich, and explore the phenomenal and temporal character of our affective experiences. When we are upset, for example, we may seek the comfort of friends, a familiar environment (a favorite park, cafe, or worship space), drink some Belgian beer, read poetry or a religious text, practice yoga, or listen to a specific playlist on our MP3 player. We do these things not merely out of habit but also because these practices and resources afford regulating our mood toward a desired end-state. For example, if someone enjoys drinking Belgian beer, a cold bottle of their favorite Tripelstyle ale not only affords grasping, drinking, and satiating thirst. In light of their aesthetic preferences and previous experiences, it also affords positive affect-regulation; it is perceived as a resource for enriching and extending their positive mood. Of course, for someone who (inexplicably) dislikes the taste of Belgian beer, the bottle will be perceptually encountered in a slightly different way. It will still be experienced as graspable and drinkable - but it will instead show up as a resource for eliciting negative affect, as something that will potentially dampen or ruin their current mood. ${ }^{2}$

A central way we experience and navigate our world therefore involves perceiving opportunities to manipulate our affective states by manipulating our affordance spaces. More specifically, we experience things and spaces as affording regulative possibilities for affective (1) niche construction, (2) scaffolding, and in some cases (3) incorporation. All three of these concepts can help clarify the character of some affective disturbances in psychopathology, especially their connection with the material environment. We consider them in more detail now.

\section{Constructing affective affordance spaces}

Organisms manipulate their environment by refining existing affordances and creating new ones. These manipulative practices create an organism's niche: a self-styled environment tailored to reflect the organism's needs and constrain their affordance spaces. All organisms engage in niche construction when they build things like nests, holes, paths, webs, dams, and chemical environments (Laland, Odling-Smee, Feldman 2000). Niches reflect and organize the organism's distinctive way of life, and a niche that supports one particular form of life may not be compatible with another. A

\footnotetext{
${ }^{2}$ Something like this is what Rietveld seems to have in mind when he speaks of things and spaces as having an "affective allure" that determines which kinds of activities they potentially solicit (Rietveld 2008, p. 977).
} 
niche is therefore not identical with the habitat of an organism; habitats don't depend upon the input of the organism. Niches, on the other hand, are relational. For Gibson, they refer "more to how an animal lives than to where it lives. I suggest that a niche is a set of affordances... The niche implies a kind of animal, and the animal implies a kind of niche" (Gibson 1986, p. 128).

In the case of humans, we construct affective niches that both reflect and organize our affective life: from lowering the lights and playing soft music to set the mood during a romantic dinner or worship service, to intentionally wearing a confidence-boosting "power suit" before a big interview, or decorating our office with art, political posters, plants, religious icons, and family pictures. In these and many other cases, we actively modify the material and symbolic structure of our environment to modify our affective states. Of course, our environmental manipulations often involve other people, too, such as when we seek the comfort of a close friend to down-regulate our anxiety about an upcoming health procedure or share our grief over losing a loved one. We do not want to underemphasize the important role others play in regulating our affective niche. However, we here focus on manipulations of our material environment. Intersubjective disturbances in psychopathology have received increased attention in recent years (e.g., Fuchs 2010; Krueger 2018; Pienkos 2015; Ratcliffe 2015b; Salice, Henriksen 2015). But their link with the material environment has not - hence our focus.

Affective scaffolding. In everyday life, we construct affective niches by exploiting our material environments. We use things and spaces as affective scaffolding: environmental resources configured to set up, drive, and regulate affective experiences at multiple timescales (Colombetti, Krueger 2015). ${ }^{3}$ We play music, drink wine, paint walls, read poetry, wear specific clothing, and gravitate to familiar places to evoke and regulate specific feelings. From a scaffolded perspective, the ongoing feedback we receive from many of these resources plays an active structuring role in the development and character of our experience. This feedback can have functional significance, too, such as when it helps us realize capacities (e.g., augmented forms of self-regulation) that we may not otherwise have without this feedback (Krueger 2014).

There are several dimensions to our scaffolding practices. To see how so, consider a case study: decorating our office. Many of us manipulate the

${ }^{3}$ Discussions of affective scaffolding flow from discussions of cognitive scaffolding, which investigate the many ways we engineer our environment to amplify and regulate (i.e., scaffold) our cognitive abilities (Sterelny 2010). 
material structure of our office to scaffold our epistemic capacities, such as when we arrange the books on our shelves by author, organize piles of notes and articles by research project, or use a second computer monitor to enhance our information-processing abilities. But our manipulations can have affective significance, too. If we want to establish a calm and welcoming atmosphere, for example, there are many ways to do this: choosing specific artworks to adorn the walls, placing plants strategically around the room, streaming calm ambient music, maintaining a level of soft lighting, and even arranging furniture and bookcases to create a regulative space in which this kind of experience is reliably elicited and maintained. The affordance space within our office in this way both reflects and organizes our affective choices; it is individualized. Additionally, by setting it up the way we do, we ensure that our office affords entrenchment or comfortable "settling into" as we go about our work and let the regulative scaffolding around us (e.g., the low lights, music softly humming along in the background) maintain our desired mood and focus. Finally, that niche is adapted not only to our individual affective needs and desires but also those of others. It affords entrenchment at both the individual and collective level - such as when a colleague borrows our office for a sensitive meeting with a student, knowing that it will provide a calming atmosphere.

This is just one example of affective niche construction. We construct affective niches throughout our life, in everyday contexts of work, play, and rest. What is important here is that these practices are cases where the things and spaces act directly on aspects of our affective states and modulate their character and temporal development. Our affective states are multi-dimensional. They are comprised of multiple factors, including bodily processes (e.g., changes in autonomic nervous system activity, behavioral expressions, etc.), states of action readiness (dispositions to act in certain ways), evaluations or appraisals, and a subjective or experiential dimension (Scherer 2009). Affective scaffolding exerts a regulatory impact on all of these factors. ${ }^{4}$

For example, wearing brightly-colored clothing can help cope with dark winters and Seasonal Affective Disorders. Color affects moods (Valdez, Mehrabian 1994), and tactile qualities of clothing contribute to the release of chemicals that lower stress levels. Similarly, a favorite handbag can function as affective scaffolding (Kaufmann 2011). Handbags contain individualized collections of technologies chosen specifically to regulate affect: good luck charms scaffold peace of mind and our ability to appraise and cope

\footnotetext{
${ }^{4}$ A comprehensive discussion of this point would take us too far afield. For additional discussion, see Colombetti, Krueger 2015.
} 
with difficult situations; snippets of personal notes or letters from loved ones scaffold fond memories and feelings of nostalgia; and small weapons or tools scaffold feelings of confidence and security, and also regulate our experience of relevant action possibilities (e.g., in the face of a threat). Likewise, office workers in shared or open plan office settings routinely use music to construct "auditory bubbles" (Dibben, Haake 2013). These private soundworlds reclaim individual space, block out environmental distractions by creating a preferred auditory environment conducive to work, and regulate attention, affect, and energy.

These observations highlight how we use things and spaces around us to scaffold our affective experiences by constructing affective niches. Importantly for our purposes, these practices are transformative. When we act on the affordances this scaffolding presents, our "bodily-affective style" (Maiese 2016) - our habitual ways of experiencing, expressing, regulating, and sharing affective states - may differ dramatically from when we lack access to it. In other words, our bodily-affective style is not fixed but rather fluidly adapts and changes as we negotiate different niches.

For example, at the interpersonal level, our style will change - often dramatically - when participating in a military drill, sporting event, or political rally versus enjoying a casual night out with family and friends or commiserating with our partner after a difficult day at work. As Slaby (2016) observes, we may even find that the habits and character of our style (e.g., ways of speaking about or expressing emotions) are shaped by background forces, norms, and expectations impacting us without our full awareness and consent. Our style fluidly adapts to our changes in our material niche as well. For instance, music streaming in the background reliably scaffolds our attention, affect, and behavior during an intense workout in the gym. If the battery in our MP3 player or smartphone dies, however, we will be jolted out of our activity and forced to recalibrate our body-affective style in relation to an affordance space suddenly deprived of the regulative resources we normally trust will be there, working in the background as expected. In other words, we must abruptly change our bodily-affective style to generate internal resources needed to refocus our attention and summon the energy and motivation to finish our workout. Likewise, compare changes in the style of a musician playing their own instrument versus an unfamiliar one for the first time, or a professional chef preparing an elaborate meal in the well-appointed kitchen of her restaurant versus the home of a friend.

These observations clarify how practices of individualization and entrenchment together generate an implicit affective trust in our niche. When skillfully inhabiting our self-styled affective niches, we trust that they will reliably set up, drive, and regulate our affective experiences in the ways we intend them to - hence our surprise when something goes wrong. Moreo- 
ver, this affective trust allows us to incorporate our individualized scaffolding into our day-to-day practices, that is, to integrate these resources into our activities so that they can do some of the affective work on our behalf. Since the possibility of incorporation - and the affective trust it solidifies is disturbed in some psychiatric disorders, it's worth considering this final concept in more detail.

Affective incorporation. Manipulating our affective niche is a transformative practice that alters not only our environment but also our bodilyaffective style. The notion of "incorporation" helps further illuminate the dynamics of this transformation. Within the phenomenological tradition, "incorporation" refers to the lived body's capacity to take something else into itself - a process that reconfigures both how we experience our bodies as well as what we can do with them. For example, we routinely incorporate new skills and habits that alter the configuration of our embodied agency: learning how to play a musical instrument, cook, speak in sign language, dance the waltz, use a hammer, throw a baseball, or even simply how to walk down the stairs without assistance (Colombetti 2016). This process of "habit-incorporation" expands the range of things we can do with our bodies in different contexts; it reconfigures our embodied agency and the range of affordances we detect within a given niche. When we learn to walk down stairs on our own, for example, we feel that the world suddenly affords free movement in a way it didn't before we incorporated the relevant skills and habits. 5

In addition to habit-incorporation, phenomenologists also discuss another form of incorporation: "object-incorporation" (Colombetti 2016). It occurs when we incorporate material objects into our lived body. MerleauPonty offers a number of examples: a woman spontaneously ducking when walking through a door to avoid damaging the feather in her hat; negotiating a tight space while driving without needing to get out of our car and compare the width of the lane with that of the fender; and a blind person skillfully navigating their environment with a cane (Merleau-Ponty 2012, p. 144). According to Merleau-Ponty, in these cases the hat, car, and cane are no longer experienced as objects separate from our body. Instead, they have been incorporated into our body's skill set as "voluminous powers" (Merleau-Ponty 2012, p. 144). The cane, for example, becomes experientially transparent and is now the perceptual vehicle through which the blind person engages with their world. According to Merleau-Ponty, the individ-

${ }^{5}$ Conversely, losing skills and habits - such as in illness or old age - also reconfigures our embodied agency and the range of affordance spaces we can access (Carel 2013). 
ual's "body-schema" (schéma corporel), or first-person awareness of themselves as an embodied subject, acquires new habits and skills by incorporating the cane into itself - and the individual's affordance space is subsequently reconfigured. The individual can reach, probe, explore, and navigate spaces that would otherwise be inaccessible because "the cane's furthest point is transformed into a sensitive zone, it increases the scope and the radius of the act of touching" (Merleau-Ponty 2012, p. 144). For Merleau-Ponty, the possibility of habit- and object-incorporation emphasizes the malleability of the body-schema and the way that reconfigurations of our embodied agency change how we respond to the solicitations of our affordance space.

Processes of habit- and object-incorporation also have affective significance. Consider hiking down a steep path covered in slippery gravel (Colombetti 2016). The equipment we use to engage with that affordance space scaffolds both agency and affect. If we wear proper hiking boots, the path will open up to our experience as affording walking down with confidence. But if we wear flat-soled tennis shoes, the path will not afford walking down with the same ease and we will instead experience it as more treacherous. In both cases, the continual feedback we receive from our shoes regulates our affective engagement with that environment; it structures an "affective frame" (Maiese 2016) regulating both how we feel and how that affordance space shows up for us via this feeling (i.e., as affording confident walking vs. a nervous descent).

We also incorporate objects into our affect-regulatory practices, in the sense that these objects become a habitual, and often experientially transparent, part of how we manage our affective states - as when a musician regularly uses her instrument to work through her affective states (Roberts 2015), a devout Catholic habitually down-regulates his anxiety by praying the Rosary and manipulating his ever-present prayer beads, or an individual riding a crowded bus regularly listens to her MP3 player to elevate her mood and occlude the outside world (Krueger forthcoming). In these cases, objects and environments contribute to our practices of regulating and stabilizing our affective life by providing reliable feedback designed to help us maintain our desired affective state. ${ }^{6}$

\footnotetext{
${ }^{6}$ It is arguably possible to regard object-incorporation as coming in degrees, phenomenologically speaking. A skilled musician who spends hours every day practicing with the same instrument, or a person who puts in their hearing aids every morning upon waking, will incorporate these objects in a much more intimate way than someone who only occasionally picks up a guitar or listens to their MP3 player during (infrequent) bouts of exercise. Likewise, in the case of an individual who spends many hours performing the same work-related tasks in a familiar environment (e.g., a professional chef in her kitchen) versus someone still in the pro-
} 
In sum, we regularly manipulate the material structure of our environments to construct affective niches: affordance spaces set up to predictably scaffold and regulate our experience at multiple timescales. We may even come to incorporate some of this affective scaffolding into our bodyschema - a process that shapes not only our experience of agency and affect but also how the world shows up in relation to our agency and affect (i.e., as presenting or occluding different affordances). As we will now see, the dynamics of affective niche construction, scaffolding, and incorporation can become disturbed in psychopathology.

\section{Affective affordances and psychopathology: two case studies}

Wittgenstein claimed that the world of those who are happy is different from those who are not (Wittgenstein 1922/2001, 6.43). In light of the previous analysis, we argue that there is a sense in which this comment is literally true. Two cases studies - clinical depression and schizophrenia - will help clarify how so. People suffering from depression and schizophrenia can be said to inhabit different worlds from others insofar as they inhabit different - often profoundly different - affordance spaces. More specifical$l y$, these individuals suffer from a disturbance of their ability to experientially inhabit and interact with affective niches the rest of us take for granted, including the material scaffolding distinctive of these niches. ${ }^{7}$ This disturbance leads to a diminishment of their self-regulative competence and affective functioning. As we will see, at least some of these problems appear to stem from subtle subject-centered, body-schematic disturbances. But as our analysis of incorporation indicated, body-schemas are not fixed; they fluidly adapt to and are reconfigured by things and spaces we interact with. To understand the regulative dynamics responsible for these affective disturbances, therefore, a more holistic approach is needed - one that focuses not simply on individualistic or internal functioning but also on the way affective function (or dysfunction) is regulated by structures and feedback loops linking individuals with their niche.

cess of customizing her new workspace. One way to mark degrees of incorporation is the extent to which object(s) become experientially transparent when absorbed into the subject's lived body, i.e., the more transparent the object becomes in experience, the more incorporated it also becomes (compare the feeling of first putting on a new pair of shoes versus the feeling after you've worn them for a week). For more on these phenomenological dimensions and degrees of incorporation, see Colombetti 2016, De Preester 2011, and Garavito 2018.

${ }^{7}$ Again, aspects of their affective difficulties also stem from disturbances of social scaffolding, too, but that is not our focus here. See Krueger 2018, Kyselo 2015, and Ratcliffe 2017. 
To be clear, we are not suggesting that depression and schizophrenia have the same etiology or respond to identical forms of intervention and treatment. What we are suggesting, rather, is that they appear to involve a similar affective disturbance - a disruption in the way individuals relate to and incorporate their affective niche. We suggest that this recognition can help shed light on the experiential character of these conditions - their relational character - and also potentially enrich the clinical picture of depressive and schizophrenic symptoms provided by the DSM-IV-TR. Additionally, this view may have implications for intervention and treatment.

There are two steps in our argument. First, we provide evidence that people with clinical depression and schizophrenia experience significant alterations of how they experience their embodiment and agency - in other words, body-schematic disturbances. Second, we show how these alterations come with changes in the overall structure of experience. Importantly, these changes are not exclusively self-directed; they have a world-directed aspect as well. This aspect takes the form of a disturbance of the individual's affordance space, which negatively impacts their ability to skillfully interact with the scaffolding distinctive of their niche and thus benefit, both synchronically and diachronically, from the regulative stability this scaffolding affords.

Body-schematic disturbances in depression and schizophrenia. Firstperson reports of what it's like to live with depression and schizophrenia, respectively, often contain descriptions of feeling as though one inhabits a different world than others do. Severely depressed patients will say things like, "I spent an increasing amount of time alone. If I was with people, I felt as if I were surrounded by strangers on a bus... encased in a loneliness as palpable as armor" (Thompson 1996, p. 45); "It is the glass wall that separates us from life, from ourselves, that is so truly frightening in depression... It is like living in a parallel universe" (Brampton 2008, p. 171). We find similar reports in schizophrenia: "I feel disconnected", "A wall of void isolated me from everybody", "It is as if there were two worlds" (Stanghellini, Rosfort 2013, p. 246).

For our purposes, what is interesting about these narratives is that this feeling of being cut off from others appears to be related to a diminished ability to flexibly adapt to the changing dynamics of a shared world. Social engagements are felt to develop too quickly or unpredictably for the individual to be a responsive participant. This feeling is underwritten by a subthe but pervasive sense that one is consistently out of sync or bodily misaligned with others: the individual's movements, gestures, emotional expressions, and speech patterns are not spontaneously synchronized with, and regulated by, the bodily expressions of others, which serves to further in- 
tensify and maintain their felt disconnectedness (Fuchs 2013; Pienkos 2015). In other words, there is a disturbance of inter-bodily resonance that impairs the individual's ability to affect, and be affected by, others (Fuchs, Koch 2014). Accordingly, other people and social spaces are not experienced as affording the smooth, flexible interactions most of us take for granted. Instead, depressed patients say things like, "There is only emptiness around me; it fills the space between me and my husband... I am kept away from the whole world" (quoted in Fuchs 2013, p. 229). We find similar reports in schizophrenic patients (Maiese 2015; Van Duppen 2017).

Although this theme has not received a great deal of attention in the literature, this felt absence of bodily resonance also characterizes how some individuals relate to things and spaces of their material environment. For example, the phenomenon of "unworlding" provides examples of how individuals with schizophrenia become experientially unmoored from affordance spaces distinctive of their everyday niches (Sass 2014). Things and spaces no longer show up as "ready-to-hand", as affording a range of immediately perceived interactive possibilities specified by the object and context in which it's encountered. Instead, everyday objects and spaces are experienced as puzzling or devoid of meaning.

For example, some schizophrenic patients describe being drawn to the empty space surrounding people and things, instead of the things themselves (Jaspers 1963, p. 81). Others report that objects appear fragmented, flat, shifting, unrelated to one another, or somehow reduced to their geometrical qualities and drained of practical salience (Silverstein, Demmin, Skodlar 2017):

Everything around me is immobile. Things appear isolated, each one in itself, without suggesting anything. Certain things which ought to evoke memory, evoke an immense number of thoughts... remain isolated. They are more understood than experienced (Minkowski 1970, p. 276).

As a result of these experiences, the individual is "unworlded" to the extent that they lose access to a shared affordance space, one in which objects and spaces have a common experiential pull. Instead of feeling a bodily resonance with the world - perceiving the environment as a shared field of interactive possibilities - things have instead "lost their names, their functions, their meanings"; they are now cognitively understood (i.e., as being the kind of objects they are) without "suggesting anything", without indicating possibilities to both affect and be affected.

We find similar descriptions of unworlding in depression narratives. To be clear, schizophrenic and depressive forms of unworlding have distinct 
phenomenological features that ought not be conflated (Sass, Pienkos 2013a, 2013b). ${ }^{8}$ Nevertheless, in both cases individuals seem to feel that their grip on the world has somehow become narrower or less taut than it ought to be. In particular, depressed individuals often report feeling that things are unreachable or far away, beyond the scope of their capacity to skillfully engage with them.

For example, a middle-aged man writes:

[W] hen you're really depressed, you know, if you're in your bedroom and someone said there's a million dollars on the other side of the room and all you have to do is swing your feet over the edge of the bed, and walk over and get the million, you couldn't... I mean you literally couldn't (Karp 1996, p. 30).

Other reports suggest a more focal narrowing of one's affordance space: "There is the feeling that your life 'contracts' - you stop seeing it as an expansive project and it all zeroes in on feelings of despair" (quoted in Slaby, Paskaleva, Stephan 2013, p. 12); "You look at the world, the array of things that you could do and they're completely meaningless to you. They are as meaningless to you as if you were an earthworm" (Karp 1996, p. 32). Some narratives even seem to echo the erosion of familiarity we find in schizophrenic reports (Cutting 2002, p. 155).

In both depression and schizophrenia, these unworlding experiences are related to body-schematic disturbances. As we've seen, modifications of the body-schema - whether by object-incorporation or psychopathology modulate how individuals experience and interact with their affordance spaces. Body-schematic disturbances have long been recognized as core features of schizophrenia. Individuals with schizophrenia exhibit less facial and vocal expressiveness than do people without schizophrenia - and as noted previously, they have difficulty mirroring and synchronizing their expressions with others (Kring, Elis 2013). One reason for this difficulty is likely the experiential distance many people with schizophrenia feel from their body (Krueger, Henriksen 2016). Although the character and articulation of this alienation may vary, reports nevertheless suggest a persistent feeling of diminished bodily self-intimacy. They describe feeling as though they are not wholly present to, or integrated with, their body: "[I]t's like I'm not in my body or not attached to it. It's like my body is an appendix that hangs below me" (Henriksen, Nordgaard 2016, p. 268). Sometimes this diminished self-intimacy also takes the form of an experience of one's body in a hyper-objectified or quasi-mechanical way: "I walk like a machine... when I am walking, I look at my legs which are moving forward; I

\footnotetext{
${ }^{8}$ We return to some of these phenomenological differences below.
} 
fear to fall by not moving them correctly" (Parnas 2003, p. 227). The oscillation between these two forms of diminished bodily self-intimacy appears fundamental to the dynamics of schizophrenic self-disorder (de Haan, Fuchs 2010).

Although anomalous experiences of embodiment are not recognized by current classification and diagnostic systems, body-schematic disturbances are nevertheless also a core feature of depression (Doerr-Zegers, Irarrázaval, Mundt, Palette 2017). Depressed individuals often describe their experience in vivid bodily terms: they continually feel "tired", "heavy", "lethargic", "exhausted", and report feeling a general sluggishness or lack of embodied vitality (Ratcliffe 2015a, p. 76). But these disturbances can take on a more articulated character that aligns them closely with descriptions we find in schizophrenic narratives - particularly descriptions in which depressed individuals experience their body in a hyper-objectified or quasi-mechanical way. Depressed individuals can feel as though they inhabit a body that has lost its fluidity, mobility, and flexibility; instead of bodily resonating with interactive possibilities afforded by their environment, the body is felt to be an impediment standing between self and world.

For example, a depressed patient describes the following experience:

There in the parking lot I was standing at attention. I was being made to move; there was nothing for it to move. My legs snapped out stiffly, one by one, in sidelong kicks... My arms traced long stiff arcs through the sky; my elbows dropped woodenly into my ribs... I must have resembled some short-circuited windshield wiper, or some marionette gone awry. But who - where - was the puppeteer? Who was in control of this body? (Smith, 1999 p. 18).

Other descriptions of this hyper-objectified embodiment are subtler but nevertheless indicate a similar experience. One individual says that, in the grip of his depression, his body felt like "the emotional equivalent of a dislocated limb" (Shenk 2001, pp. 248-249); another says, "My body began to feel as dull and dead as the bookshelf or the hardwood floor" (Stenke 2001, p. 63).

Again, there are some important phenomenological differences between body-schematic disturbances in schizophrenia and depression, respectively. Whereas the diminished self-intimacy distinctive of the former consists in the oscillation between loss of affective integration with one's body, on one hand, and a hyper-objectified form of bodily experience on the other which then leads the schizophrenic individual to feel detached from their body - the depressed individual instead appears to feel over-identified with their body (Sass, Pienkos 2013b, p. 122). In other words, they feel as though they are continually sinking into their body (as when one is very fatigued), and thus increasingly incapable of summoning the animacy and 
spontaneity that characterizes how healthy lived bodies engage with their affordance spaces (Aho 2013).

Despite these phenomenological differences, however, body-schematic disturbances in schizophrenia and depression share a common structural feature: they are not exclusively self-directed affairs. An important takeaway lesson is therefore that these disturbances are Janus-faced. They alter both the individual's sense of embodied agency as well as how the world shows up in relation to this altered agency. Instead of being comfortably immersed in everyday norm-governed contexts of action and routine - supported and guided by things and spaces in their everyday niche - individuals instead feel that a rift has opened up between themselves and the rest of the world. They experience the world as offering up fewer interactive possibilities than before; their affordance spaces have diminished and the individual struggles to connect with meaningful surroundings the rest of us take for granted. As we will see, this "unworlding" impacts their ability to use the scaffolding distinctive of their niche to regulate their affective states.

\section{Disruptions of the affective niche}

As we've seen, body-schematic disturbances in schizophrenia and depression alter how individuals experience their embodied agency as well as how the world shows up in relation to their embodied agency. Specifically, the experience of diminished bodily self-intimacy appears to go hand-inhand with the experience of diminished affordance spaces. Things and spaces no longer invite spontaneous and flexible engagements but are now experienced as closed off, inaccessible, or as no longer affording predictable patterns of interaction. Clearly, losing access to practical affordances within the material environment plays a central role in reinforcing the individual's sense of losing their bodily resonance with the world (Kim, Kim 2017). However, an aspect of this experience that has not received much attention in the literature is the impact unworlding experiences have upon the individual's capacity to regulate and sustain their affective life in relation to the environment as well.

A central lesson from our earlier considerations is that the rich network of material scaffolding that makes up our individualized niches - along with the capacity to reliably access this scaffolding - is crucial for maintaining regulative stability within our everyday affective life. This is because the things and spaces around us, when arranged in particular configurations, take over much of the regulative work on our behalf. Again, we individualize and become comfortably entrenched within our niches and thus allow ourselves to delegate part of the regulative process to this scaffolding while we focus on other things. But this process is easy to overlook. Most of us 
seamlessly negotiate our changing affordance spaces - and skillfully engage with the scaffolding that is part of it - from one moment to the next, without much reflection on the dynamics of this process. We wake up, turn on the lights, gaze out the window at the sunrise, make coffee, turn on our computer, get in the shower, stream music, choose clothing, and in myriad other ways follow this trail of affordances throughout our day - until something goes wrong (our computer won't boot up, we've lost the keys to our office, the battery in our MP3 player dies, etc.), and we are abruptly forced to recalibrate our interaction with our affordance space. In other words, our day-to-day activities unfold against a background of affective trust that the things in our environment will do what we want them to when we want them to do it. This affective trust secures our feeling of at-home-ness in the world and helps maintain our affective equilibrium. But this trust - and the affective equilibrium that flows from it - is precisely what's diminished or missing in both schizophrenia and depression. Without this pervasive trust, one's experience of reality "wobbles" (Ratcliffe 2015a) and becomes unsteady insofar as the individual's affordance space has now been profoundly reconfigured or narrowed. As a consequence, one's affective life is increasingly destabilized without trustworthy access to the resources provided by this scaffolding.

Depression. Consider first how this experiential loss of affective trust may develop in depression. Benson, Gibson, and Brand (2013) show that the persistent feeling of being suicidal in depression - beyond simply exhibiting suicidal ideation - involves a disturbance of the body-schema that deadens the individual's embodied agency and connection to their affordance space. Within this feeling, the body comes to the foreground in ways that can disrupt or impede action. For instance, the body can be experienced as a persistent source of pain or discomfort that is difficult to inhabit and that the person wants to escape from. In these cases, the strain of dealing with this persistent bodily discomfort, along with the need to regulate suicidal thoughts and feelings, depletes the individual's energetic resources and diminishes their ability to enact even mundane everyday actions:

I generally do not think about suicide for extended periods, but force myself to "snap out of it". Controlling this urge is mentally tiring, and ironically one of the things I wish to escape via suicide; I've tried so very, very, hard, months and months have gone by can't think straight any more my brain feels overloaded, exhausted so exhausted my body has got so weak (Benson, Gibson, Brand 2013, p. 67).

Echoing the diminished bodily self-intimacy described previously, others report feeling as though their body loses its animating principle or motivational affect; it's felt to be numb, hollow, or corpse-like: "I felt very numb and closed off... At times it felt as if there was a hole in me and all my ener- 
gy was just perpetually gushing out of me, leaving me this little shell of a person" (Benson, Gibson, Brand 2013, p. 68).

These body-schematic disturbances harbor a correlative world-directed aspect as well (Jacobs 2013). Not only do these disturbances diminish the individual's affordance space: "I feel very disconnected to the world, as if I'm floating, not quite there or visible to others" (Benson, Gibson, Brand 2013 , p. 65). They also reconfigure which affordances stand out as salient (Benson, Gibson, Brand 2013, p. 71). For example, bridges, tall buildings, train tracks and busy streets, packets of medication, knives and other utensils, guns, ropes or other items that may be used to end one's life become prominent while other features of the material environment recede to the background. Moreover, not just the salience but even the basic meaning of everyday objects can change. A window that normally affords opening or gazing out now affords jumping; sewing needles or kitchen knives loses their practical salience and instead become instruments of self-harm.

What is important for our purposes is that this reconfiguration of the individual's affordance space has regulative significance, too. The severely depressed individual is no longer integrated with her environment in a smooth and unthinking way; instead, she loses bodily resonance with - and crucially, affective trust in - the things and spaces around her. Her ability to easily incorporate environmental resources into day-to-day activities is compromised: "It feels as though I am separate from anything and anyone else... detached and unable to make connections with any other thing"; I want to reach out to the world, but it isn't there to reach out to..." (Benson, Gibson, Brand 2013, p. 65). Even mundane things that would normally bring pleasure or help to brighten the individual's mood now become sources of constant distraction and anxiety, continually nudging the individual toward negative or disorganized affect. The window, once a source of mood-elevating light and calming views of the street, now beckons relentlessly as a means to a quick death; the knife that once elicited feelings of pride and nostalgia at the memory of its purchase during a trip to Tokyo now demands that it be allowed to slice open human flesh; a favorite song that once reliably elicited positive associations and memories now brings to mind broken relationships and personal failures. The environment as a whole is drained of its affective allure: "Living with depression is like living in black and white when everyone else is living in color" (Benson, Gibson, Brand 2013, p. 73). And in light of this reconfigured affordance space, ordinary concentration on mundane tasks becomes difficult. For the nondepressed person, as Benson, Gibson, and Brand (2013) note, many of our day-to-day activities are "pre-reflective, guided by cues from our environment and our bodies" (Benson, Gibson, Brand 2013, p.72). The depressed individual, however, is continually disrupted by cues or solicitations for sui- 
cidal thoughts and actions, which interrupts her actions and depletes her affective and self-regulative resources. And since she no longer enjoys trustworthy access to mood-elevating affordances and scaffolding, she cannot assume that the things and spaces around her will help with the process of restoring affective equilibrium. Without reliable access to this affective scaffolding, she has in this way lost access to an external regulative mechanism.

Schizopbrenia. A similar disruption can be found in schizophrenia. However, as we will see, this disruption has some distinct phenomenological features. For one thing, it is often more pronounced than in depressed individuals. One reason for this is that people with schizophrenia, unlike depressed individuals, often exhibit more profound perceptual anomalies. One individual describes his experience of the environment this way: "Everything is in bits. You put the picture up bit by bit in your head. It's like a photograph that's torn in bits and put together again... If I move there's a new picture that I have to put together again" (McGhie, Chapman 1961, p. 106). Another says that "[S]ights, sounds, thoughts, and feelings don't go together. No organizing principle takes successive movements in time and puts them together in a coherent way from which sense can be made" (Saks 2007, p. 13).

As a consequence of this perceptual disorganization - coupled with their body-schematic disturbances - schizophrenic individuals lose their practical grip on the things around them. The world is no longer experienced as presenting a dynamic landscape of changing affordances that resonate with bodily significance. Instead, things and spaces become saturated with a pervasive sense of strangeness and unfamiliarity, and their affordance qualities diminish or disappear entirely: "When, for example, I looked at a chair or a jug, I thought not of their use or function - a jug not as something to hold water and milk, a chair not as something to sit in - but as having lost their names, their functions, their meanings..." (Sechehaye 1970, pp. 55-56).

As in depressive unworlding, what is lost in schizophrenic unworlding is not simply access to the world's practical significance but, once again, its affective and regulative significance, too. Things and spaces no longer afford self-regulative possibilities because they are not experienced as scaffolding one can trust to elicit and regulate predictable responses. ${ }^{9}$ As a result of this unworlding, the individual's affective orientation to the environment

9 Ratcliffe's (2017) phenomenological analysis of disturbances of the "anticipationfulfillment" structure of experience describes a similar phenomenon. 
changes. Possibilities for individualization and entrenchment are lost, leading to a breakdown of affective trust.

The character of this disturbance can be understood by looking at case vignettes like the following:

A 32-year old patient reports that at the age of 16, he had become more and more uncertain about whether his personal things really belonged to him or had somehow been exchanged by others. When buying books, he was not sure if the salesman had not secretly replaced the ones he had chosen; so he had to give them away and always buy new ones. When leaving things on his school-desk inattentively, he later began to doubt whether they were still the same, and had to throw them away. More and more he lost the trust in his environment. (Fuchs 2005, p. 101).

Part of the distrust the patient experiences has to do with ownership of his belongings; it expresses his delusional fear that someone is replacing his belongings with duplicates. However, there is an important affective dimension to this distrust that may not be apparent at first glance. The affective character of this patient's distrust is directly tied to the instability of the patient's available material scaffolding. He is continually plagued by the fear that things in his environment are being replaced; he thus adopts a hypervigilant stance from which he is continually on the lookout for clues that would affirm this feeling. Like the severely depressed person considered previously, mundane things no longer invite smooth interactions but instead become sources of constant distraction and anxiety. Accordingly, the patient is no longer able to individualize and incorporate his self-styled network of affective scaffolding. Instead of comfortably inhabiting affordance spaces set up to reliably regulate predictable affective experiences, he must instead devote excessive attention and energy to hyper-reflectively scrutinizing his niche. This hyper-reflectivity, in turn, shuts down possibilities for skillful entrenchment. Accordingly, the world and things in it no longer afford smooth self-regulative possibilities or function as trustworthy "affective stabilizers". The surrounding space becomes unpredictable and foreboding, leading to a disorganized and unstable affective style - and an overall diminishment of regulative function.

Before concluding this section, we should note that the character of schizophrenic unworlding indicates a subtle but important phenomenological difference from depressive unworlding. ${ }^{10}$ This difference can be brought out by looking at de Haan et al.'s (2013) distinction between a global "landscape" versus a local "field" of affordances (see also Rietveld, Kiverstein 2014). The former refers to the set of all possible affordances potentially

${ }^{10} \mathrm{We}$ are grateful to a reviewer for raising this point. 
open to a particular form of life (humans, cats, dogs, earthworms, etc.). The latter is a more restricted, individual-centered notion. It refers to affordances available to an individual in a particular time and place, specified by that individual's current skills, interests, and concerns. So, for participants in a distinctively human form of life, hills afford running in order to increase cardiovascular fitness. They are part of the general landscape of affordances available to members of this form of life. But they are not necessarily available to all members of this form of life at all times and in all places. An individual may currently be in poor physical shape, for instance, or have excessive family and work responsibilities that leave no time for exercise. Hillsas-runnable may therefore may not be part of that individual's current field of affordances.

Both depressive and schizophrenic unworlding, as we've seen, involve experiential disturbances of the individual's field of affordances, which impacts how they engage with their distinctive affective niche. But at least in some cases, schizophrenic unworlding takes on a more articulated character. It involves a global disturbance not just of the individual's distinctive field of affordances but also of their ability to access a shared landscape of human affordances. In other words, it is characterized by a basic loss of affective trust in, and vital contact with, reality as a whole. Whereas the affective salience of specific affordances can change in depression (e.g., the window affords jumping out of, the knife cutting one's wrist), schizophrenia appears to involve a more fundamental loss of access to the shared network of affordances that comprise a distinctively human form of life (e.g., things are experienced as "as having lost their names, their functions, their meanings"). The phenomenological intensity and complexity of first-person reports - which involve severe disturbances of how individuals experience space and objects, time and events, other persons, language, atmosphere (sense of reality, familiarity), and existential orientation (values, attitudes) speaks to the far-reaching, global character of schizophrenic unworlding (Sass et al. 2017).

The takeaway lesson from these reports is that despite some important phenomenological differences that must be preserved, unworlding experiences in both depression and schizophrenia nevertheless also share some important structural features. Specifically, both appear to involve a loss of affective trust in the world. Experiencing reliable access to the constituents of our material environment is crucial for our ability to stabilize and regulate our affective life on a short and long-term basis. As we've seen, things and spaces often play an ineliminable role in scaffolding what we feel and how we feel it. However, reliable access to this scaffolding is in various ways disturbed in severe depression and schizophrenia. As a result, individuals not only lose access to the practical significance of the built environ- 
ment but also to its regulative significance, too - and without the ability to incorporate these external resources into their self-regulative strategies, the stability of their affective life is profoundly disrupted.

\section{Conclusion}

We have argued that the affective character of psychopathological conditions like severe depression and schizophrenia may be related, in part, to the individual's disturbed relationship with their environment - specifically, a disturbed relationship with the regulative resources normally afforded by the things and spaces around them. What are the benefits of this "scaffolded" approach to affective disturbances in psychopathology?

There are, we propose, potentially at least two. First, this approach can offer theoretical resources for better characterizing the causal complexity of affective disorders in psychiatric illnesses, which may lead to more satisfactory explanations (Sprevak 2011). For proponents of biological psychiatry, understanding and treating psychiatric disorders - including their affective dimensions - is a matter of isolating underlying neurological failures. However, acknowledging the ineliminable role that environmental scaffolding plays in organizing and supporting our affective experiences on a day-today basis suggests the need to adopt a more relational approach to affective disturbances. Such an approach sees the disturbance in question as involving processes both inside and outside of the individual, that is, within the dynamics of their (disturbed) experience of embodiment as well as the (disturbed) character of their engagement with the people, things, and spaces around them. A scaffolded approach thus puts useful pressure on the idea that the aetiology or pathological nature of the disturbance is contained entirely in the individual.

Second, a scaffolded approach may impact our thinking about new possibilities for intervention and treatment. If affective disorders are in fact relational, in that their aetiology and/or pathology involves disturbances of how the individual experiences and engages with environmental resources, pharmacological interventions - which exclusively target specific brain regions - may on their own be inadequate. Instead, what may be more effective, from a scaffolded perspective, are holistic strategies that directly address not simply neural dysfunction but also features of the individual's (disturbed) embodiment and the character of their dysfunctional relationship with the environment.

In this vein, Maiese (2015) has recently argued for the need to explore "bottom-up treatment methods", as she terms them. These methods, which address the dynamics of bodily movements and affect, consist of therapeutic methods like yoga, music, and dance/movement therapies. Maiese ar- 
gues that these are embodied strategies that help individuals deepen their sense of bodily ownership and agency, feel more at home in and engaged with their social and material environment, and develop more effective ways of expressing, sharing, and regulating their emotions (see also Galbusera, Finn, Fuchs 2016). While more research is needed, there is some supporting evidence. For example, individuals with mental disorders show an increased use of music for emotion-regulation when compared with healthy controls (Gebhardt, Kunkel, Georgi 2014). This existing inclination to incorporate musical scaffolding into one's repertoire of self-medicating strategies can be productively fed into more formal intervention strategies. There is some evidence that music therapy - consisting of improvised sessions creating music with a therapist - can lead to at least short-term reductions in general symptoms (e.g., depression) and negative symptoms in schizophrenic patients (Talwar et al. 2006). Embodied strategies such as these may in this way help individuals reintegrate with some of the affective niches that make up our shared world. ${ }^{11}$

Department of Sociology, Philosophy, and Anthropology University of Exeter, United Kingdom

E-mail: j.krueger@exeter.ac.uk E-mail: g.colombetti@exeter.ac.uk

\section{References}

Aho, K.A. 2013: "Depression and Embodiment: Phenomenological Reflections on Motility, Affectivity, and Transcendence", Medicine, Health Care, and Philosophy, 16 (4), pp. 751-759.

Benson, O., Gibson, S., Brand, S.L. 2013: "The Experience of Agency in the Feeling of Being Suicidal", Journal of Consciousness Studies, 20 (7-8), pp. 56-79.

Brampton, S. 2008: Shoot the Damn Dog: A Memoir of Depression, London, Bloomsbury Publishing Plc.

Carel, H. 2013: "Bodily Doubt", Journal of Consciousness Studies, 20 (7-8), pp. 178-197.

Chemero, A. 2009: Radical Embodied Cognitive Science, Cambridge, MA, MIT Press.

${ }^{11}$ We are grateful for the critical feedback from the anonymous reviewers. Their input greatly improved the final version of this paper. 
Colombetti, G. 2016: "Affective Incorporation”, in J.A. Simmons, J.E. Hackett (eds.), Phenomenology for the Twenty-First Century, Basingstoke, Palgrave Macmillan UK, pp. 231-248.

Colombetti, G., Krueger, J. 2015: "Scaffoldings of the Affective mind", Philosophical Psychology, 28 (8), pp. 1157-1176.

Cutting, J. 2002: The Living, the Dead, and the Never-alive: Schizophrenia and Depression as Fundamental Variants of These, Mill Wood, Forest Publishing Company.

de Haan, S., Fuchs, T. 2010: "The Ghost in the Machine: Disembodiment in Schizophrenia - Two Case Studies", Psychopathology, 43 (5), pp. 327-333.

de Haan, S., Rietveld, E., Stokhof, M., Denys, D. 2013: “The Phenomenology of Deep Brain Stimulation-induced Changes in OCD: An Enactive Affordance-based Model", Frontiers in Human Neuroscience, 7, pp.1-14.

De Preester, H. 2011: "Technology and the Body: the (Im)Possibilities of Reembodiment", Foundations of Science, 16 (2-3), pp. 119-137.

Dibben, N., Haake, A.B. 2013: "Music and the Construction of Space in Office-Based Work Settings”, in G. Born (ed.), Music, Sound and Space, Cambridge, Cambridge University Press, pp. 151-168.

Doerr-Zegers, O., Irarrázaval, L., Mundt, A., Palette, V. 2017: "Disturbances of Embodiment as Core Phenomena of Depression in Clinical Practice", Psychopathology, 50 (4), pp. 273-281.

Fuchs, T. 2005: "Corporealized and Disembodied Minds: A Phenomenological View of the Body in Melancholia and Schizophrenia", Philosophy, Psychiatry, E Psychology, 12 (2), pp. 95-107.

Fuchs, T. 2010: "Subjectivity and intersubjectivity in Psychiatric Diagnosis", Psychopathology, 43 (4), pp. 268-274.

Fuchs, T. 2013: "Depression, Intercorporeality, and Interaffectivity", Journal of Consciousness Studies, 20 (7-8), pp. 219-238.

Fuchs, T., Koch, S.C. 2014: "Embodied Affectivity: On Moving and Being Moved", Frontiers in Psychology, 5 (508), pp. 1-12.

Galbusera, L., Finn, M.T., Fuchs, T. 2016: "Interactional Synchrony and Negative Symptoms: An Outcome Study of Body-Oriented Psychotherapy for Schizophrenia", Psychotherapy Research: Journal of the Society for Psychotherapy Research, 28 (3), pp. 457-469.

Gallagher, S. 2017: Enactivist Interventions: Rethinking the Mind, Oxford, Oxford University Press.

Garavito, M.C. 2018: "Incorporating Others: What an Extended Self Tells Us About Intersubjectivity", Adaptive Behavior.

Gebhardt, S., Kunkel, M., Georgi, R. von 2014: "Emotion Modulation in Psychiatric Patients Through Music", Music Perception: An Interdisciplinary Journal, 31 (5), pp. 485-493. 
Gibson, J.J. 1986: The Ecological Approach to Visual Perception, Hillsdale, Lawrence Erlbaum Associates.

Henriksen, M.G., Nordgaard, J. 2016: "Self-Disorders in Schizophrenia", in G. Stanghellini, M. Aragona (eds.), An Experiential Approach to Psychopathology - What is it like to Suffer from Mental Disorder?, New York, Springer, pp. 265-280.

Hufendiek, R. 2016: "Affordances and the Normativity of Emotions", Synthese, 194 (11), pp. 4455-4476.

Jacobs, K. 2013: “The Depressive Situation”, Frontiers in Psychology, 4 (429), pp. 1-11.

Jaspers, K. 1963: General Psychopathology, Eng. trans. by J. Hoenig and M.W. Hamilton, Manchester, Manchester University Press.

Karp, D. 1996: Speaking of Sadness: Depression, Disconnection, and the Meanings of Illness, Oxford, Oxford University Press.

Kaufmann, J.-C. 2011: Le sac: un petit monde d'amour, Paris, Jean-Claude Lattès.

Kim, N.-G., Kim, H. 2017: "Schizophrenia: An Impairment in the Capacity to Perceive Affordances", Frontiers in Psychology, 8 (1052), pp. 1-19.

Kring, A.M., Elis, O. 2013: "Emotion Deficits in People with Schizophrenia", Annual Review of Clinical Psychology, 9, pp. 409-433.

Krueger, J. 2014: "Affordances and the Musically Extended Mind", Frontiers in Psychology, 4 (1003), pp. 1-13.

Krueger, J. 2018: "Schizophrenia and the Scaffolded Self", Topoi.

Krueger, J. forthcoming: "Music as Affective Scaffolding", in D. Clarke, R. Herbert, E. Clarke (eds.), Music and Consciousness II, Oxford, Oxford University Press.

Krueger, J., Henriksen, M.G. 2016: "Embodiment and Affectivity in Moebius Syndrome and Schizophrenia: A Phenomenological Analysis", in J.A. Simmons, J. Hackett (eds.), Phenomenology for the Twenty-First Century, London, Palgrave Macmillan, pp. 249-267.

Kyselo, M. 2015: "The Enactive Approach and Disorders of the Self - The Case of Schizophrenia", Phenomenology and the Cognitive Sciences, 15 (4), pp. 591-616.

Laland, K.N., Odling-Smee, J., Feldman, M.W. 2000: "Niche Construction, Biological Evolution, and Cultural Change", The Behavioral and Brain Sciences, 23 (1), pp. 131-146

Maiese, M. 2015: Embodied Selves and Divided Minds, New York, Oxford University Press.

Maiese, M. 2016: “Affective Scaffolds, Expressive Arts, and Cognition”, Frontiers in Psychology, 7 (359), pp. 1-11.

McGhie, A., Chapman, J. 1961: "Disorders of Attention and Perception in Early Schizophrenia", The British Journal of Medical Psychology, 34 (2), pp. 103-116. 
Merleau-Ponty, M. 2012: Phenomenology of Perception, Eng. trans. by D.A. Landers, New York, Routledge.

Minkowski, E. 1970: Lived Time: Phenomenological and Psychopathological Studies, Evanston, Northwestern University Press.

Parnas, J. 2003: "Self and Schizophrenia: A Phenomenological Perspective", in T. Kircher, A. David (eds.), The Self in Neuroscience and Psychiatry, Cambridge, Cambridge University Press, pp.218-241.

Pienkos, E. 2015: "Intersubjectivity and Its Role in Schizophrenic Experience", The Humanistic Psychologist, 43 (2), pp. 194-209.

Ratcliffe, M. 2015a: Experiences of Depression: A Study in Phenomenology, Oxford, Oxford University Press.

Ratcliffe, M. 2015b: "The Interpersonal World of Psychosis", World Psychiatry: Official Journal of the World Psychiatric Association, 14 (2), pp. 176-178.

Ratcliffe, M. 2017: Real Hallucinations: Psychiatric Illness, Intentionality, and the Interpersonal World, Cambridge, MA, MIT Press.

Rietveld, E. 2008: "Situated Normativity: The Normative Aspect of Embodied Cognition in Unreflective Action", Mind, 117 (468), pp. 973-1001.

Rietveld, E., Kiverstein, J. 2014: “A Rich Landscape of Affordances”, Ecological Psychology, 26 (4), pp. 325-352.

Roberts, T. 2015: "Extending Emotional Consciousness", Journal of Consciousness Studies, 22 (3-4), pp. 108-128.

Saks, E. R. 2007: The Center Cannot Hold: My Journey Through Madness, New York, Hyperion.

Salice, A., Henriksen, M.G. 2015: "The Disrupted 'We': Schizophrenia and Collective Intentionality", Journal of Consciousness Studies, 22 (7-8), pp. 145-171.

Sass, L.A. 2014: "Self-Disturbance and Schizophrenia: Structure, Specificity, Pathogenesis". Schizophrenia Research, 152 (1), pp. 5-11.

Sass, L.A., Parnas, J. 2003: "Schizophrenia, Consciousness, and the Self", Schizophrenia Bulletin, 29 (3), pp. 427-444.

Sass, L.A., Pienkos, E. 2013a: "Space, Time, and Atmosphere A Comparative Phenomenology of Melancholia, Mania, and Schizophrenia, Part II", Journal of Consciousness Studies, 20 (7-8), pp. 131-152.

Sass, L.A., Pienkos, E. 2013b: "Varieties of Self-Experience: A Comparative Phenomenology of Melancholia, Mania, and Schizophrenia, Part I", Journal of Consciousness Studies, 20 (7-8), pp. 103-130.

Sass, L., Pienkos, E., Škodlar, B., Stanghellini, G., Fuchs, T., Parnas, J., Jones, N. 2017: "EAWE: Examination of Anomalous World Experience", Psychopathology, 50 (1), pp. 10-54.

Scherer, K.R. 2009: "The Dynamic Architecture of Emotion: Evidence for the Component Process Model”, Cognition and Emotion, 23 (7), pp. 1307-1351. 
Sechehaye, M. 1970: Autobiography of a Schizophrenic Girl, Eng. trans. by G. Rubin-Rabson, New York, New American Library.

Shenk, J.W. 2001: "A Melancholy of Mine Own", in N. Casey (ed.), Unholy Ghost, New York, William Morrow \& Company, pp. 242-255.

Silverstein, S.M., Demmin, D., Skodlar, B. 2017: "Space and Objects: On the Phenomenology and Cognitive Neuroscience of Anomalous Perception in Schizophrenia (Ancillary Article to EAWE Domain 1)", Psychopathology, 50 (1), pp. 60-67.

Slaby, J. 2016: "Mind Invasion: Situated Affectivity and the Corporate Life Hack", Frontiers in Psychology, 7 (266), pp. 1-13.

Slaby, J., Paskaleva, A., Stephan, A. 2013: "Enactive Emotion and Impaired Agency in Depression”, Journal of Consciousness Studies, 20 (7-8), pp. 33-55.

Smith, J. 1999: Where the Roots Reach for Water, New York, North Point Press. Sprevak, M. 2011: "Neural Sufficiency, Reductionism, and Cognitive Neuropsychiatry”, Philosophy, Psychiatry, E Psychology, 18 (4), pp. 339-344.

Stanghellini, G., Rosfort, R. 2013: Emotions and Personhood: Exploring Fragility, Making Sense of Vulnerability, Oxford, Oxford University Press.

Stenke, D. 2001: "Poodle bed", in N. Casey (ed.), Unholy Ghost, New York, William Morrow \& Company, pp. 60-74.

Sterelny, K. 2010: "Minds: Extended or Scaffolded?", Phenomenology and the Cognitive Sciences, 9 (4), pp. 465-481.

Talwar, N., Crawford, M.J., Maratos, A., Nur, U., McDermott, O., Procter, S. 2006: "Music Therapy for In-patients with Schizophrenia: Exploratory Randomised Controlled Trial", The British Journal of Psychiatry: The Journal of Mental Science, 189 (5), pp. 405-409.

Thompson, T. 1996: The Beast: A Journey Through Depression, New York, Plume. Valdez, P., Mehrabian, A. 1994: "Effects of Color on Emotions", Journal of Experimental Psychology: General, 123 (4), pp. 394-409.

Van Duppen, Z. 2017: "The Intersubjective Dimension of Schizophrenia", Philosophy, Psychiatry, E Psychology, 24 (4), pp. 399-418.

Wittgenstein, L. 2001/1922: Tractatus Logico-Philosophicus, Eng. trans. by D.F. Pears and B.F. McGuinness, London-New York, Routledge Classics. 